\title{
A Study of Evaluation of Two-dimensional Quality Elements of Convention Tourism Based on Kano Model-A Case Study on Macao
}

\author{
Kuang Tingyue ${ }^{1}$ \\ ${ }^{1}$ Faculty of Business, City University of Macau, Macau 999078, China
}

\begin{abstract}
Macao is an international tourism city. With the burgeoning development of meetings, incentives, conventions and exhibitions (MICE) industry over these years, convention tourism has become an integral part of tourism products in Macao. With a case study on convention participants in Macao and Kano model as the study approach, this study investigates the participants' expectations for the quality of convention tourism in Macao and the two-dimensional quality of convention tourism products in Macao. In this study, a total of 202 valid questionnaires were classified based on the two-dimensional attributes, and the customer satisfaction coefficient was calculated as the basis for quality improvement of convention tourism. Based on the study findings, this study presents convention organizers and relevant government departments with targeted suggestions.
\end{abstract}

\section{Introduction}

Meetings, incentives, conventions and exhibitions (MICE), incepted in the Great Exhibition of 1851 held in London, have experienced a tremendous development over the past nearly 170 years. A report from the International Exhibition Industry Association (UFI) suggested that the global exhibition industry had a direct economic output of US\$197.5 billion in 2018, ranking $56^{\text {th }}$ among the largest industries across the globe, and it ranked higher than industries such as machine tools and medical device. MICE economy, emerging with the global economic integration, is known as the barometer and bellwether of regional economy. MICE, the acronym for "Meetings, Incentives, Conventions and Exhibitions", is a novel theme-based special tourism product as a result of multiple types of conventions, expositions, exhibitions and other activities. (Ying,2003). With the development of international tourism industry recently, convention tourism boomed dramatically, and has received an enormous amount of attention by tourism sectors in all countries. To date, convention tourism has been regarded as an important indicator of the competitiveness and civilization and the principal backbone for revitalization and development of tourism.

${ }^{1}$ Government of Macao Special Administrative Region Statistics and Census Service. Statistics on Conventions and Exhibitions, Season 4, 2019
As the leading entertainment and tourism destination that offers a variety of recreational activities, tourism and hospitality services, Macao is seeking to further diversify its tourism, and is making good headway in MICE industry. The MICE industry is highly valued by the Macao SAR Government, and receive full support from the state. In 2001, the Macao SAR Government proposed to develop the MICE industry. In 2010, the SAR Government established the "Committee for Development of Conventions and Exhibitions". Macau Trade and Investment Promotion Institute (IPIM) joined hands with the committee for an overall development of the MICE industry, and significant progress has been made in the past more than ten years. In 2019, a total of 1,536 conventions and exhibitions were held in Macao, a year-on-year increase of 109 conventions and exhibitions (up 7.6\%). The total number of convention participants and attendees reached 2.003 million, a year-on-year fall by $5.4 \%$. Among them, there were 1,459 conventions, with an average duration of 1.5 days and a total of 292,000 participants; there were 58 exhibitions attracting a total of 1.689 million attendees, with an average duration of 3.4 days; there were 19 incentives attracting a total of 22,000 attendees, with an average duration of 3.0 days. During 2009-2019, the number of participants/attendees in Macao's MICE industry increased from 661,000 to 2.003 million, an over threefold increase. ${ }^{1}$

${ }^{2}$ Note: Since 2016, the statistics on the convention and exhibition activities of Government of Macao Special Administrative Region Statistics and Census Service have been added to the "Incentive Activities" project 
Table1. Number of MICE in Macao from 2009 to 2019

\begin{tabular}{|c|c|c|c|c|c|}
\hline & \multicolumn{3}{|c|}{ MICE } & \multirow{2}{*}{$\begin{array}{c}\text { Number of } \\
\text { participants/attendees } \\
\text { (Unit: 10,000) }\end{array}$} \\
\cline { 2 - 6 } Year & Conventions & Exhibitions & $\begin{array}{c}\text { Incentive } \\
\text { activities }\end{array}$ & Total & 66.1 \\
\hline 2009 & 1405 & 80 & 0 & 1485 & 80.6 \\
\hline 2010 & 1342 & 57 & 0 & 1399 & 127.8 \\
\hline 2011 & 994 & 51 & 0 & 1045 & 161.3 \\
\hline 2012 & 961 & 61 & 0 & 1022 & 203.4 \\
\hline 2013 & 964 & 66 & 0 & 1030 & 261.5 \\
\hline 2014 & 968 & 87 & 0 & 1055 & 248.1 \\
\hline 2015 & 831 & 78 & 0 & 909 & 172.2 \\
\hline 2016 & 1195 & 55 & $26^{\mathrm{a}}$ & 1276 & 190.1 \\
\hline 2017 & 1285 & 51 & 45 & 1381 & 212.2 \\
\hline 2018 & 1342 & 60 & 25 & 1427 & 200.3 \\
\hline 2019 & 1459 & 58 & 19 & 1536 & \\
\hline
\end{tabular}

Data source: Government of Macao Special Administrative Region Statistics and Census Service

According to previous studies, the characteristics of conventions, exhibitions, festival activities vary greatly. With a focus on convention tourism, this study explores the criteria of convention participants for evaluation of the quality of convention tourism from the perspective of convention participants based on the actual conditions of the MICE industry in Macao. In this study, Kano attractive quality model was used as the evaluation method to prepare a scale for evaluation of the quality of convention tourism. Additionally, convention participants in Macao were interviewed using questionnaires, so as to help the industry to understand the various demands of participants for convention tourism, and identify attractive quality factors that are essential to customer satisfaction. The objectives of this study are as follows: (1) preparation of a reliable and valid evaluation scale for quality of convention tourism based on the literature and the actual conditions of convention tourism in Macao. (2) processing of investigational data, classification of quality elements based on Kano two-dimensional quality model, and identification of quality elements (e.g., attractive quality and one-dimensional quality). (3) identification of the two-dimensional quality characteristics of service quality elements for convention tourism in Macao through the analysis, and provision of suggestions for improvement of quality of convention tourism in Macao for convention organizers and planners.

\section{Literature review}

\subsection{Convention tourism}

The key of convention tourism lies in convention, and tourism is a derivative. Convention tourism can be divided into convention tourism in a broad sense and convention tourism in a narrow sense. The former refers to MICE tourism, while the latter refers to "Convention Travel", i.e., tourism simply due to organization and attendance of various conventions (Dai et al., 2005). The convention tourism mentioned in this study is the latter.

Regarding the research contents of convention tourism, scholars at home and abroad primarily focus on participants, convention planners, convention destinations, convention organizations, distribution channels of convention tourism, and the impact of convention tourism.

Liang et al. (2018) believe that the convention tourism industry has become fiercely competitive, an in-depth understanding of behaviors of convention participants is necessary, and the factors of locations and total cost are significantly correlated with the participation and decisions of convention participants. Government is a significant convention planner. Recently, countries all over the world attached great importance to the development of MICE industry. The factors affecting convention planners' selection of destination play a instrumental role. Fortin and Ritchie (1976) were the first ones to explore convention planners' selection of convention destination. Andrew et al. (2002) believe that the quality, cost, and accessibility of convention facilities and the image of convention venue should be considered. Additionally, the support services for convention and accessibility of convention venues (Para et al., 2014), the convenience of flight schedules, and the risks of convention disruption (G.I.et al., 2019) are the leading factors for the selection of convention destination. Based on the importance-performance analysis (IPA), Lee et al. (2016) indicate that affordability is the most important attribute among the seven attributes for competitiveness of convention destination (i.e., accessibility, availability of facilities, affordability, appropriate services, pleasant environment, scenic spots, and attractive image). Convention \& Visitor Bureau (CVB), a convention 
organization established in multiple countries, has been investigated by numerous scholars. For example, Lee et al. (2016) explored the relationship between CVB and its stakeholders, and found that target conflicts and interdependence would affect the collaborative relationships, thereby affecting the performance of CVB. Some issues emerge as a result of the impact of convention tourism market, including inflation, exhibition effects, traffic congestion, increase in crime and cost, and redistribution of social and economic benefits. A growing number of scholars propose to develop green conventions from the perspective of sustainable development (Gracan et al., 2016). Through the investigation of convention tourism and sustainable development, the factors that represent green behaviors(e.g., green attitude, social norms, ecological concerns, individual morality and obligations, and green behaviors)can be explored (Heesup et al., 2019).

Although convention tourism exhibits an important economic significance and booms rapidly, studies on convention tourism were rarely reported in academic circles. Over the past few decades, the inequality between the burgeoning development of convention industry and the research level remained high, and the number of empirical articles rose rapidly, while the number of conceptual articles rarely increased. Additionally, studies on the quality of convention tourism related to this theme were rarely reported, and only Guo et al. (2009) evaluated the quality of convention tourism based on the four characteristics (i.e., destination (Shanghai) of convention tourism, convention arrangement, convention facilities and services, and convention venue (Yangpu District,
Shanghai)) from the perspective of participants. The questionnaires in this study were designed by reference to the study conducted by Guo et al. (2009).

\subsection{Kano model}

Kano model, originated from the motivator-hygiene theory of work attitudes proposed by Herzberg et al. (1959), is the most extensively used tool for identification of customer satisfaction attributes. In October 1979, Professor Noriaki Kano from Tokyo University of Science and his colleague Fumio Takahashi, inspired by the motivator-hygiene theory of work attitudes, published the article "Motivator and Hygiene Factor in Quality", which initially introduced the criteria for satisfaction and dissatisfaction into the field of quality management. In January 1984, this article was officially published in The Journal of the Japanese Society for Quality Control (Vol.14), marking the establishment of Kano model and the feasibility of attractive quality theory.

The schematic diagram for Kano model (Fig. 1) shows that $\mathrm{X}$-axis represents the availability of quality elements, and $\mathrm{Y}$-axis represents the customer (user) satisfaction. The closer it is to the left on the $\mathrm{X}$ axis indicates a higher degree of scarcity of a quality element, while the closer it is to the right indicates a higher degree of availability of a quality element. The closer it is to the top on the y axis indicates a higher degree of customer satisfaction, while the closer it is to the bottom on the y axis indicates a higher degree of customer dissatisfaction.

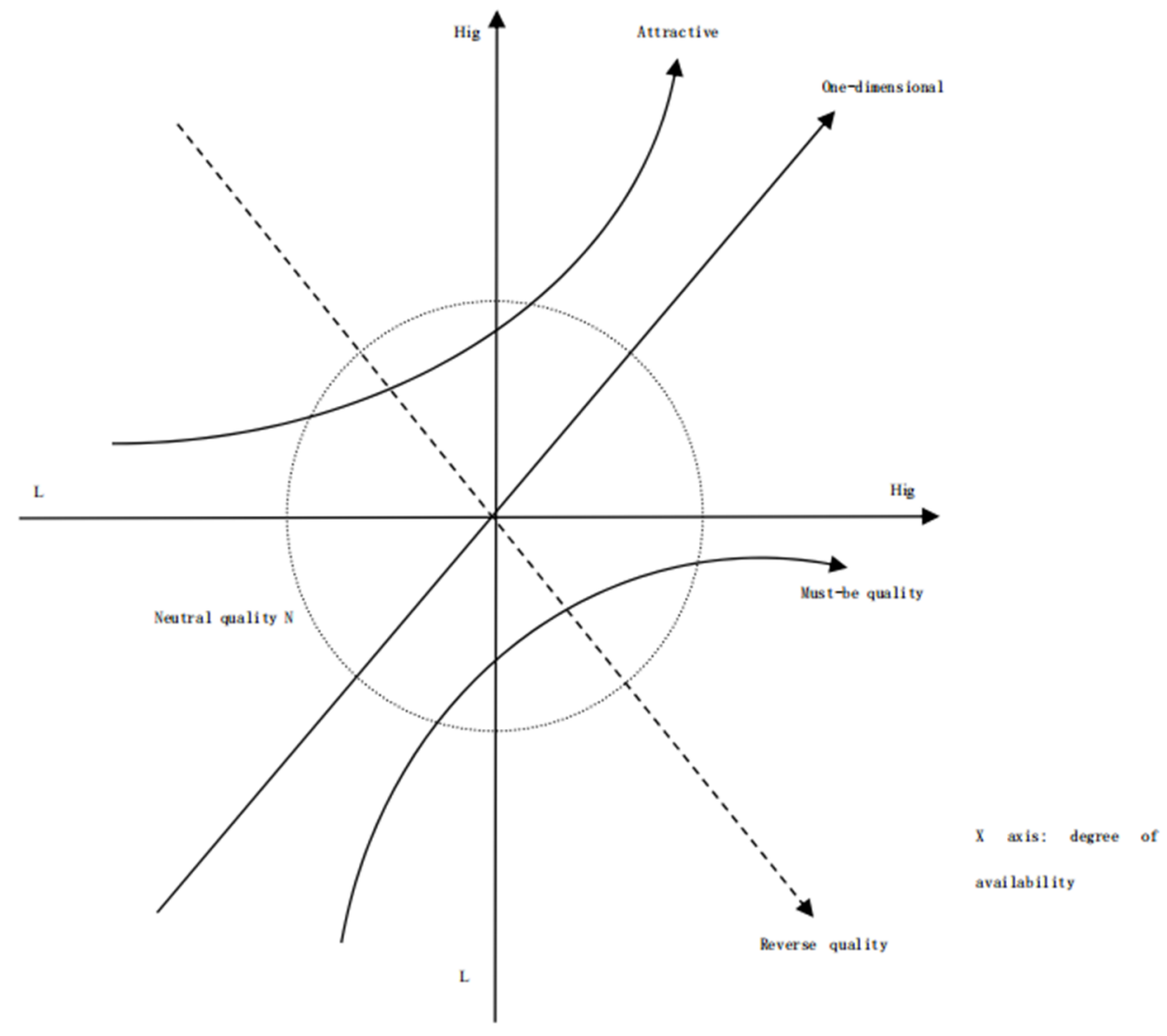

Fig 1. Customer satisfaction-Kano model

Date source: Berger et al.,1993; Cai et al. (2013) 
According to the relationship between different types of quality characteristics and customer satisfaction, Professor Noriaki Kano divides the quality characteristics of products/services into five categories:

Attractive quality element. These attributes provide satisfaction when achieved fully, but do not cause dissatisfaction when not fulfilled. These are attributes that are not normally expected, for example, a thermometer on a package of milk showing the temperature of the milk. Since these types of attributes of quality unexpectedly delight customers, they are often unspoken.

One-dimensional quality element. These attributes result in satisfaction when fulfilled and dissatisfaction when not fulfilled. These are attributes that are spoken and the ones in which companies compete. An example of this would be a milk package that is said to have ten percent more milk for the same price will result in customer satisfaction, but if it only contains six percent then the customer will feel misled and it will lead to dissatisfaction.

Must-be quality elements. These attributes are taken for granted when fulfilled, and result in dissatisfaction when not fulfilled. For example, a milk bag leaks. If package leaks occur, customers are dissatisfied. However, If package leaks do not occur, customers are just neutral. Since customers expect these attributes and regard them as basic attributes, they probably not inform companies of such quality attributes when asked about them.

Neutral quality element. These attributes refer to aspects that are neither good nor bad, and they do not result in either customer satisfaction or customer dissatisfaction.

Reverse quality element. These attributes refer to a high degree of achievement resulting in dissatisfaction and to the fact that not all customers are alike. For example, some customers prefer high-tech products, while others prefer the basic model of a product and will be dissatisfied if a product has too many extra features.

Traditionally, customer satisfaction is considered as "more leads to satisfaction", which is different from that indicated by Kano model. In Kano model, "attractive quality element" is regarded as a competitive strategy to improve competitiveness, "one-dimensional quality element" should be possessed as much as possible and the lack should be avoided, and "must-be quality element" must be possessed, otherwise it will result in customer dissatisfaction. If the three quality elements are possessed and strengthened, customer satisfaction will be improved. Therefore, operators must attach great importance to the quality elements, and should be seeking to possess them. Regarding the other two elements, the availability and non-availability of "Neutral quality element" will not exert much influence, and it can be selectively excluded in case of the pressure of cost competition; the availability of "Reverse quality element" should be avoided.

\section{Study methods and design}

In this study, an integrated study method, including Kano model and statistical analysis using Statistical Package for the Social Sciences (SPSS), was used to evaluate and investigate the quality of convention tourism in Macao. This study method is primarily used to help convention organizers to evaluate the satisfaction of participants, so as to identify the weak points in the quality elements that should be strengthened, and develop innovative and competitive service projects through the identification of attractive quality characteristics.

\subsection{Scope of study and subjects}

Macao possesses a rich tourism resources and world-class major international convention and exhibition venues, attracting numerous tourists who attend conventions in Macao every year. In this study, an empirical study method was adopted. With the support from the convention \& exhibition organizers and tourists who attend conventions in Macao as the study subjects, this study investigates the opinions from the participants, so as to help convention organizers to further improve their service projects.

\subsection{Questionnaire design and sampling method}

Questionnaire is a way to collect data through asking the interviewees to state their views or opinions according to the designed questions. Through structured standardized questionnaires and sampling methods, customer information can be collected directly, and the results are highly general (Wang, 2006). Therefore, based on the aforementioned literature (Guo et al., 2009), repeatedly solicited opinions from relevant professionals, and integration of theories and practices, the questionnaire is designed upon approval by experts.

Finally, this study sets the variables that are used by representatives of convention participants for evaluation for the quality of convention tourism as the four dimensions: attractiveness of convention tourism destination, attractiveness of convention venue, attractiveness of convention facilities and services, and attractiveness of convention arrangement, and there are a total of 19 measurable variables. To perform the demand analysis using Kano Model, the data collection using the Kano questionnaire is required. In the Kano questionnaire, questions are positively and negatively raised, so as to explore the changes in interviewees' attitudes regarding whether the content of a quality element (measurable variable) is sufficient. According to the study results obtained by Matzler and Hinterhuber(1998), the interviewees' attitudes are categorized as "like", "take it for granted", "neutral", "tolerable", and "dislike". Interviewees will receive several possible answer combinations based on the positive and negative questions for each demand, and the investigators will provide the corresponding classification definition for each answer combination based on the actual conditions, so as to identify the demand category.

Based on the study results obtained by Matzler and Hinterhuber(1998), this study uses the following judgment matrix to classify the quality elements. 
Table2. Kano evaluation table

\begin{tabular}{|c|c|c|c|c|c|c|}
\hline \multirow{2}{*}{$\begin{array}{c}\text { Product requirements } \\
\downarrow\end{array}$} & \multicolumn{5}{|c|}{ Dysfunctional issues } \\
\cline { 2 - 7 } & Like & $\begin{array}{c}\text { Take it for } \\
\text { granted }\end{array}$ & Neutral & Tolerable & Dislike \\
\hline \multirow{3}{*}{ Functional } & Like & Q & A & A & A & O \\
\cline { 2 - 7 } & $\begin{array}{c}\text { Take it for } \\
\text { granted }\end{array}$ & R & I & I & I & M \\
\cline { 2 - 7 } & Neutral & R & I & I & I & M \\
\cline { 2 - 7 } & Tolerable & R & I & I & I & M \\
\cline { 2 - 7 } & Dislike & R & R & R & R & Q \\
\hline
\end{tabular}

A: Attractive quality; O: One-dimensional quality; M: Must-be quality; I: Indifferent quality; R: Reverse quality; Q: Questionable results

In this study, a pre-test was performed prior to the official distribution of the questionnaires. The pre-test questionnaire in this study comprises 19 questions. The students, teachers and business people who previously conducted conference tourism in this university were investigated. A total of 120 valid questionnaires were distributed and recovered, with an effective recovery rate of $100 \%$. The Alpha coefficient of the pre-test questionnaire ranged from 0.711 to 0.805 , exhibiting a high reliability of the scale. In the second half of 2019 , this study was strongly supported by the organizers, and a total of 300 questionnaires were distributed in a largescale convention held in Macao, and 231 questionnaires were recovered, with a recovery rate of $77.0 \%$. After the questionnaires with default values were rejected, there were totally 202 valid questionnaires, with an effective questionnaire rate of $67.33 \%$.

\section{Data analysis}

In this study, the reliability and validity are analyzed based on the valid questionnaires recovered, and the quality attributes are classified based on Kano twodimensional model, and finally the customer satisfaction coefficient is calculated.

\subsection{Reliability and validity test}

The Alpha coefficient of the scale dimension in the official questionnaire is $0.691-0.832$, indicating that the reliability of this scale is acceptable. The KMO values measured in the official questionnaire are above 0.7 , and the $\mathrm{P}$ value corresponding to Bartlett's spherical test is 0.000 , indicating that the exploratory factor analysis can be performed. Additionally, the questionnaires in this study are designed based on numerous literature results and opinions from experts in this line and industry insiders. Therefore, the questionnaire can cover the study topics.

\subsection{Classification of Kano two-dimensional quality}

The 19 questions in the recovered questionnaires are classified based on Kano model, the discussion was performed from the perspective of convention participants, the classification attributes of different quality services are analyzed using the coding methods, and the results are shown in Table 3. The method for calculation of the classification ratio of Kano quality attributes is based on subjects' views on the adequacy and inadequacy of each service quality. Subjects' views on the quality elements are accumulated, and the percentage of each quality element is calculated. Finally, quality elements with a high percentage are regarded as the desired quality elements. For example, the statistical analysis of the 202 questionnaires shows that regarding the first question "Good urban security",31 people(15.35\%),59 people(29.21\%),99 people(49.01\%),11 people(5.45\%),2 people $(0.99 \%)$, and 0 people regarded this service quality as "attractive quality", "one-dimensional quality", "mustbe quality", "indifferent quality", "Invalid quality", and "Reverse quality", respectively. Finally, "must-be quality" $(49.01 \%)$ was regarded as the classification attribute.

\subsection{Calculation of customer satisfaction coefficient}

Theoretically, quality improvement aims at customer satisfaction, namely, all requirements proposed by customers are met. However, in view of conditions and costs in practical operations, the industry often gives priority to implement targeted actions for quality elements demonstrating the most improvement value and the most obvious effect. In Kano Model, it is generally considered that the addition of the ratios of "attractive quality" and "one-dimensional quality" indicates the degrees of satisfaction of customers when they possess the quality element, and the addition of the ratios of "one- 
dimensional quality" and "must-be quality" indicates the degrees of dissatisfaction caused by customers' insufficient provision of this quality element. Matzler and Hinterhuber (1998) further defined the index for improvement of the two qualities as customer satisfaction coefficient (CSC). CSC can serve as an indicator of quality elements that are worthy of improvement, namely, quality requirements that can lead to a dramatic increase in satisfaction and a sharp fall in dissatisfaction can be identified after specific improvement. In this study, satisfaction increment index (SII) and dissatisfaction decrement index (DDI) are used to investigate the quality elements that should be prioritized to be improved. The calculation is performed in accordance with formulas (1) and (2):

\section{$\mathbf{S I I}=(\mathbf{A}+\mathbf{O}) /(\mathbf{A}+\mathbf{O}+\mathbf{M}+\mathbf{I})$ \\ Formula (1) \\ $\mathbf{D D I}=(\mathbf{O}+\mathbf{M}) /(\mathbf{A}+\mathbf{O}+\mathbf{M}+\mathrm{I}) \times \mathbf{( - 1})$ \\ Formula(2)}

Where, the satisfaction index values range from 0 to 1 . The closer it is to 1 indicates the greater impact of this demand on customer satisfaction. However, the dissatisfaction index values range from -1 to 0 , and the closer it is to -1 indicates the greater impact of this demand on customer dissatisfaction. Therefore, the aforementioned indexes can be used to identify quality elements that exert influences on customer satisfaction at the time of adequacy or inadequacy of the quality elements, and a greater influence indicates that the quality elements should be strengthened.

According to formulas (1) and (2), CSC including SII and DDI values can be obtained, as shown in Table 3 .

Table3. Kano quality attribute category and customer satisfaction coefficient

\begin{tabular}{|c|c|c|c|c|c|c|c|c|c|}
\hline \multirow{2}{*}{ Variables } & \multicolumn{6}{|c|}{ Percentage of Kano Quality Attributes Category } & \multirow{2}{*}{ Category } & \multirow{2}{*}{ SII } & \multirow{2}{*}{ DDI } \\
\hline & $\mathbf{A}$ & $\mathbf{0}$ & M & I & $\mathbf{R}$ & $\mathbf{Q}$ & & & \\
\hline a1 Good public safety & $15.35 \%$ & $29.21 \%$ & $49.01 \%$ & $5.45 \%$ & $0.00 \%$ & $0.99 \%$ & $\mathrm{M}$ & 0.45 & -0.79 \\
\hline a2 Reachability of destination & $5.45 \%$ & $44.06 \%$ & $39.60 \%$ & $10.40 \%$ & $0.00 \%$ & $0.50 \%$ & 0 & 0.50 & -0.84 \\
\hline $\begin{array}{l}\text { a3 Convenience of urban } \\
\text { transport }\end{array}$ & $0.99 \%$ & $39.60 \%$ & $56.93 \%$ & $2.48 \%$ & $0.00 \%$ & $0.00 \%$ & M & 0.41 & -0.97 \\
\hline $\begin{array}{l}\text { a4 Convenience for access to } \\
\text { nearby cities }\end{array}$ & $13.86 \%$ & $30.69 \%$ & $49.50 \%$ & $4.95 \%$ & $0.00 \%$ & $0.99 \%$ & $\mathrm{M}$ & 0.45 & -0.81 \\
\hline a5 High popularity of the city & $28.22 \%$ & $34.16 \%$ & $26.24 \%$ & $0.99 \%$ & $10.40 \%$ & $0.00 \%$ & 0 & 0.70 & -0.67 \\
\hline $\begin{array}{l}\text { a6 Attractiveness of convention } \\
\text { theme }\end{array}$ & $29.70 \%$ & $21.29 \%$ & $38.12 \%$ & $9.90 \%$ & $0.00 \%$ & $0.99 \%$ & M & 0.52 & -0.60 \\
\hline a7 Speaker's high reputation & $37.13 \%$ & $22.28 \%$ & $27.23 \%$ & $9.90 \%$ & $0.99 \%$ & $2.48 \%$ & $\mathrm{~A}$ & 0.62 & -0.51 \\
\hline a8 High-quality speech & $15.35 \%$ & $39.11 \%$ & $29.70 \%$ & $11.88 \%$ & $0.00 \%$ & $3.96 \%$ & 0 & 0.57 & -0.72 \\
\hline a9 Well-arranged sessions & $39.60 \%$ & $19.80 \%$ & $29.70 \%$ & $9.90 \%$ & $0.00 \%$ & $0.99 \%$ & A & 0.60 & -0.50 \\
\hline $\begin{array}{l}\text { a10 Appropriate duration of } \\
\text { convention }\end{array}$ & $19.80 \%$ & $43.56 \%$ & $30.20 \%$ & $5.94 \%$ & $0.00 \%$ & $0.50 \%$ & 0 & 0.64 & -0.74 \\
\hline $\begin{array}{l}\text { a11 Appropriate convention } \\
\text { schedule }\end{array}$ & $29.70 \%$ & $14.85 \%$ & $49.50 \%$ & $4.95 \%$ & $0.00 \%$ & $0.99 \%$ & $\mathrm{M}$ & 0.45 & -0.65 \\
\hline a12 Convenient Internet access & $7.43 \%$ & $39.60 \%$ & $49.50 \%$ & $2.97 \%$ & $0.00 \%$ & $0.50 \%$ & $\mathrm{M}$ & 0.47 & -0.90 \\
\hline a13 Friendly convention staff & $9.41 \%$ & $44.55 \%$ & $38.61 \%$ & $5.94 \%$ & $0.00 \%$ & $1.49 \%$ & 0 & 0.55 & -0.84 \\
\hline a14 Fast response of staff & $10.40 \%$ & $42.08 \%$ & $40.10 \%$ & $6.44 \%$ & $0.00 \%$ & $0.99 \%$ & 0 & 0.53 & -0.83 \\
\hline $\begin{array}{l}\text { a15 Good tea service in } \\
\text { convention }\end{array}$ & $32.18 \%$ & $27.23 \%$ & $22.28 \%$ & $17.33 \%$ & $0.00 \%$ & $0.99 \%$ & A & 0.60 & -0.50 \\
\hline $\begin{array}{l}\text { a16 Clear indication signs in the } \\
\text { conference hall }\end{array}$ & $7.43 \%$ & $29.70 \%$ & $19.80 \%$ & $42.08 \%$ & $0.00 \%$ & $0.99 \%$ & I & 0.38 & -0.50 \\
\hline $\begin{array}{l}\text { a17 Various shopping facilities } \\
\text { nearby }\end{array}$ & $38.61 \%$ & $18.81 \%$ & $30.69 \%$ & $10.89 \%$ & $0.00 \%$ & $0.99 \%$ & A & 0.58 & -0.50 \\
\hline \begin{tabular}{|l|} 
a18 Various recreational \\
facilities nearby
\end{tabular} & $44.55 \%$ & $19.80 \%$ & $24.75 \%$ & $7.43 \%$ & $0.00 \%$ & $3.47 \%$ & A & 0.67 & -0.46 \\
\hline $\begin{array}{l}\text { a19 Various local restaura } \\
\text { nearby }\end{array}$ & $22.28 \%$ & $40.59 \%$ & $25.74 \%$ & $9.41 \%$ & $0.50 \%$ & $1.49 \%$ & 0 & 0.64 & -0.68 \\
\hline
\end{tabular}

According to the calculation of CSC, we have the following findings:

(1) In dimension 1 "attractiveness of convention tourism destination", the urban image and attractiveness of Macao are reflected, and are the major elements for development of convention tourism products. The convention schedule remains the key of convention tourism. Representatives of convention participants should timely learn about the development trends of related professional fields to learn additional skills. The convention tourism destination is an additional product that can improve the quality of convention tourism and bring surprises to participants. Table 3 shows that among the five measurable variables in this dimension, there are three measurable variables in "must-be quality element" and two measurable variables in "one-dimensional quality element". Among them, the variables with a higher DDI value (absolute value) and the quality attribute categorized into "must-be quality" are a3 "convenience of urban transport" (DDI value: -0.97) and a4 "convenience 
for access to nearby cities" (DDI value: -0.81), respectively. The definition of DDI coefficient of "mustbe quality" shows that the improvement of the aforementioned two quality elements results in a sharp fall in customer dissatisfaction. In this dimension, there is no "attractive quality" element. Therefore, a5 "high popularity of the city" with a higher SII value in "onedimensional quality" element is considered as an indicator of improvement of customer satisfaction and quality.

(2) In dimension 2 "Attractiveness of convention arrangement", the relevant characteristics of convention arrangement are reflected. Table 3 shows that among the six measurable variables in this dimension, there are two measurable variables in "attractive quality element", two measurable variables in "must-be quality element", and two measurable variables in "one-dimensional quality element". In this dimension, there are two measurable variables in "attractive quality" element, namely, a7 "speaker's high reputation" and a9 "appropriate duration of convention", with the SII value approaching 1 . The definition of "attractive quality" shows that the improvement of these elements can result in a high customer satisfaction. Therefore, the priority should be given to the improvement of these elements. In the "onedimensional quality element" in this dimension, a10 "appropriate duration of convention" is worthy of attention and further investigation, because the customer satisfaction coefficient suggests that the SII and DDI values of this variable are 0.64 and 0.74 , respectively, exhibiting that the adequacy of this variable directly affects customer satisfaction.

(3) In dimension 3 "attractiveness of convention facilities and services", the characteristics of convention venue are reflected. Table 3 shows that among the five measurable variables in this dimension, there are two measurable variables in "one-dimensional quality element", one measurable variable in "attractive quality element", one measurable variable in "must-be quality element", and one measurable variable in "indifferent quality element". Among them, the variable with a higher DDI value (absolute value) and the quality attribute categorized into "must-be quality" is a12 "convenient Internet access" (DDI value: -0.90), suggesting that participants have regarded Internet service as a basic quality element, and the great resentment and dissatisfaction will be incurred if Internet service is not provided. Additionally, a15 "good tea service in convention" has been categorized into "attractive quality element".

(4) In dimension 4 "attractiveness of leisure and entertainment at the convention venue", the leisure and entertainment characteristics at the convention venue and its surroundings are reflected. Based on the urban characteristics of Macao and the convention nature, the addition of recreational and sightseeing products in convention tourism can effectively enhance the competitiveness of conventions. Table 3 shows that among the three measurable variables in this dimension, there are two measurable variables in "attractive quality element" and one measurable variable in "onedimensional quality element". This demonstrates that convention organizers should devote attention to the essential characteristics of convention tourism (i.e., the diversity of tourism elements) when it comes to the selection of convention venues. As a tourism city, Macao offers a variety of recreational activities, tourism and hospitality services, which can satisfy various demands of convention participants and effectively improve customer satisfaction.

\section{Conclusions and suggestions for future studies}

As a world tourism and leisure center, Macao enjoys congenital advantages in developing MICE industry. Additionally, the unique tourism elements of Chinese and Western cultures and customs and customs of Southern Europe in Macao significantly promote the development of MICE industry. Additionally, the MICE industry, which is highly valued by the Macao SAR Government and receive full support from the state, has become an additional backbone of Macao's economy as one of the leading industries (e.g., gambling industry) in Macao. Macao is transforming it into the preferred city known for entertainment, recreation, shopping and its exhaustive coverage of conventions and exhibitions in the AsiaPacific region.

\subsection{Conclusion}

Based on Kano two-dimensional quality model, this empirical study investigates the two-dimensional quality characteristics of the service quality elements of convention tourism products from the perspective of the convention participants, with a case study on participants in a large-scale convention in Macao.

The study conclusions are as follows:

(1) The classification results of Kano two-dimensional quality show that 18 of the 19 quality elements investigated are important quality elements that are highly valued by convention participants, including 7 "onedimensional quality" elements, 5 "attractive quality" elements and 6 "must-be quality" elements. Based on the 18 important quality elements, this study presents suggestions for improvement of service quality of MICE industry

(2) Based on the six "must-be quality" elements, the industry should fully consider the demands of convention participants, because "must-be quality" elements can directly lead to customer dissatisfaction, though they cannot improve customer satisfaction. Regarding those with a high DDI value (absolute value), such as a3 "convenience of urban transport" (DDI value: -0.97), a12 "convenient Internet access" (DDI value: -0.90), and a4 "convenience for access to nearby cities" (DDI value: 0.81 ), the industry must give priority to their quality improvement. For example, regarding a3 "convenience of urban transport", measures (e.g., special convention buses and shuttle sightseeing buses are provided) should be implemented. For a12 "convenient Internet access", although wired Internet connection devices are provided at most convention venues in Macao, they cannot provide Internet connection services for emerging mobile devices 
(e.g., Ipad). Therefore, WIFI Internet services should be provided at the convention venue. For a4 "convenience for access to nearby cities", there are currently very few channels between Macao and the mainland China, and Hong Kong or the surrounding regions, and this issue will be improved upon the completion of the construction of Hong Kong-Zhuhai-Macau Bridge (HZMB) and Guangzhou-Zhuhai-Macau Light Rail Transit. In view of this, the Macao SAR government should vigorously promote the progress of related projects.

(3) Based on the five "attractive quality" elements, the industry should actively consider the demands of convention participants, because the availability of attractive quality elements significantly contributes to the improved customer satisfaction. Among the five "attractive quality" elements, there are two "attractive quality" elements in the convention theme, suggesting that the key of convention tourism products lies in convention. Therefore, when it comes to the organization of conventions, the industry must pay attention to the specifications and connotations of conventions, highlight the industry characteristics and international reputation of conventions, determine convention topics and objectives that can reflect the latest development trend of the industry, and strive to provide participants with opportunities for career development and business exchanges, thus demonstrating the core competitiveness of convention tourism in Macao. Among the five "attractive quality" elements, there are two "attractive quality" elements in tourism theme. Tourism and leisure activities during convention, which are additional convention tourism products, can not only promote the exchanges among participants, but also enrich the convention connotation. Macao is positioned by the central government as a "World Tourism and Leisure Center". Convention organizers should provide convention participants with a three-dimensional and diverse tourism experiences based on the features of Macao. Additionally, there are a variety of unique tourism products, Monte Carlo of the Orient, world cultural heritages in the main urban districts, the urban architecture with strong customs of southern European, and a shopping paradise in the international free trade port in Macao. Convention organizers should provide convention participants with information on sightseeing tours and excursions and shopping based on their demands, so as to facilitate their tourism planning before and after convention.

\subsection{Suggestions}

This study, which is subjected to manpower, time and funds, only empirically investigates participants in a large-scale convention held in Macao, and the study method and conclusions can be used by conference organizers as the basis for improvement of their service qualities, and can serve as the references for future studies.

There are two suggestions for the shortcomings in this study, with a view to providing a reference for the future follow-up studies.
(1) The subjects' psychological defenses result in the failure to fully collect the subjects' individual characteristics. As a result, it is impossible to identify the differences of age, occupation, gender and other factors in two-dimensional quality attributes. In the follow-up studies, the statistical plan should be improved if all conditions are available, so as to verify whether there are significant differences between two-dimensional attributes and demographic characteristics, thereby conducting the targeted studies.

(2) Since the Kano questionnaire is designed in form of positive and negative questions, a considerable number of interviewees indicate that it is challenging to answer the questions. Additionally, the questionnaire is concisely designed, so as to prevent interviewees from losing patience. Therefore, a questionnaire that is objectively and scientifically designed based on the theme of "quality of convention tourism" should be employed in the future follow-up studies.

\section{Acknowledgement}

Project supported by Macao Foundation (MF1906)

\section{Author}

Kuang Tingyue, DBA, Assistant Professor, Faculty of Business at City University of Macau. Research Interests: Human Capital, Industrial Economics and Cultural Industry.

\section{References}

1. Andrew Bradley, Tim Hall, Margaret Harrison. (2002). Selling cities: promoting new images for meeting Tourism. Cities, 19(1):61-70.

2. Cai LB, Wang Q. (2013). A Study of Exhibition Service Quality Based on Refined Kano Model: A Case Study of China International Consumer Electronics Show. Journal of Ocean University of China (Social Science Edition), (5),68-75.

3. Dai GQ et al. (2005). Tourism Theory, Case and Planning of Festivals, Festival Events and Events. Beijing: Science Press.

4. Fortin, P.A., Ritchie, J.R.B. and Arsenault, J. (1976) A study of the decision process of North American associations concerning the choice of a convention site. Quebec Planning and Development Council.

5. Geoffrey I.Crouch, Giacomo Del Chiappa, Richard R.Perdued.(2019).International convention tourism : A choice modelling experiment of host city competition. Tourism Management,( 71),530-542.

6. Gracan, D., Barkiðija, M. and Dugandzic, A. (2016), "An Exploratory study of environmental awareness in business tourism", Tourism \& Hospitality Industry 2016 proceedings of Biennial International Congress in Opatija, Croatia, 2016, ProQuest, pp. 53-65. 
7. Guo YZ, Zang SN, Jiang JX. (2009). A Case Study on the Convention Tourist Quality Evaluation in Shanghai. Economic Geography, 29(9).1569-1573.

8. Heesup Han ,Soyeun Lee,Amr Al-Ansi, HyeonCheol Kim,Hyungseo Bobby Ryu,Jinkyung Jenny Kim \& Wansoo Kim.(2019).Convention Tourism and Sustainability: Exploring Influencing Factors on Delegate Green Behavior That Reduce Environmental Impacts. Sustainability, (11), 1-14.

9. Herzberg, F., Maunser, B. and Snyderman, B. (1959). The Motivation to Work, John Wiley and Sons Inc., New York, NY.

10. Kano, Noriaki \& Takahashi, Fumio (1984) Attractive Quality and Must-be Quality. The Journal of the Japanese Society for Quality Control, p39-48.

11. Lee, H.; Lee, J.; Jones, D. Exploring the interrelationship between Convention and Visitor Bureau (CVB) and its stakeholders, and CVB performance from the perspective of stakeholders. J. Travel Tour. Mark. 2016, 33, 224-249.

12. Lee, J., Choi, Y., \& Breiter, D. (2016). An exploratory study of convention destination competitiveness from the attendees' perspective: Importance-performance analysis and repeated measures of manova. Journal of Hospitality \& Tourism Research, 40(5), 589-610.

13. Liang, Henry Chuah Kun; Latip, Hamrila A.(2018).Factors Affecting Attendees' DecisionMaking in Convention Tourism Industry. Advanced Science Letters, 24(6),4414-4420.

14. Para, A., \& Kachniewska, M. (2014). Determinants of convention and conference site selection: The Polish event planner perspective. New Trends in Tourism Research-A Polish Perspective, 1, 150-162.

15. Wang MH, Chen RL, Su YH. (2006). Applying Linear Structural Equation Models to Study the Influence of Service Quality on Customer Satisfaction and Customer Loyalty-An Empirical Study of Chinese Petroleum Corporation Gas Stations. Journal of Customer Satisfaction, 2(2),4786.

16. Ying LJ. (2003). Reflections on China's MICE Tourism. Tourism Science, (1),10-12. 